\title{
Diferenciação pedagógica e a inclusão escolar em Moçambique. Um imperativo incontornável na sala de aula
}

\author{
Pedagogical differentiation and school inclusion in Mozambique: \\ A prime necessity in the classroom
}

\author{
Mónica Simão Mandlate \\ Faculdade de Educação, Universidade Eduardo Mondlane, Moçambique
}

\begin{abstract}
Resumo
Este artigo pretende apresentar o impacto da diferenciação pedagógica e a inclusão das crianças com necessidades educativas especiais (NEE) no ensino regular moçambicano. Trata-se de pesquisa exploratória baseada em entrevistas a seis professores de $5^{\mathrm{a}}$ classe, quatro formadores dos Institutos de Formação de Professores (IFP's) e dois técnicos pedagógicos do nível macro e micro, onde se analisaram os discursos, as práticas pedagógicas e a relação professor/aluno. Assim, constatou-se que os constrangimentos na implementação do ensino inclusivo moçambicano prendem-se com a formação de professores e outros intervenientes no processo educativo bem como a insipiência dos recursos financeiros, materiais e humanos para a sua materialização.

Palavras-chave: Diferenciação pedagógica; Inclusão escolar; NEE
\end{abstract}

\begin{abstract}
This article seeks to present the impact of the differentiation and the inclusion of children with special educational needs (SEN) in Mozambique. It resulted from an exploratory research based on interviews with six 5th grade teachers, four leaders of the Teacher Training Institutes, and two pedagogical technicians macro and level, where discourses, pedagogical practices, and the relationship teacher/student were analised. We concluded that the constraints in the implementation of an inclusive education in Mozambique are related to the lack of teacher training and other stakeholders in the process education and to the absence of financial, material, and human resources that would allow its implementation.
\end{abstract}

Keywords Pedagogical differentiation; School inclusion; SEN

Abordar questões de diferenciação e inclusão escolar constitui um desafio nas instituições educativas e em particular no ensino básico (EB), numa altura em que é indispensável atender à diversidade, realidade cada vez mais comum na sala de aula, considerando-a não como um obstáculo ao processo de ensino/aprendizagem, mas como fonte enriquecedora do processo educativo (Roldão \& Marques, 2000).
Pensar atualmente em diferenciação e inclusão em Moçambique, constitui ainda mais um obstáculo, e uma atitude de coragem por, pelo menos, quatro razões. Primeiro, há um grande e generalizado distanciamento entre a formação de professores em termos de abordagem dos conteúdos alusivos às NEE's e o perfil profissional dos formadores dos IFP's. Isso, por sua vez, não satisfaz aquilo que são as necessidades e exigências da diversidade dos alunos na sala de aula. Segundo, os IFP's e as respetivas escolas do (EB) defrontam-se com falta de recursos materiais, financeiros e humanos qualificados, para responder à demanda das escolas inclusivas. Terceiro, observa-se que há falta de conhecimento profundo por parte dos formadores e professores daquilo que é a abordagem inclusiva, incluindo o conceito de diferenciação pedagógica enquanto meio de inclusão escolar. Por último, nota-se a ausência das equipas multidisciplinares para potenciar as escolas e professores do EB, em estratégias inovadoras no atendimento das crianças com NEE.

Este artigo pretende evidenciar a diferenciação e a inclusão como questões centrais para a educação inclusiva. Centrando a nossa atenção na problematização das questões de diferenciação pedagógica e inclusão escolar, analisando os seus conceitos e relacionando-os com a sala de aula e a formação de professores.

Assumindo que a diferenciação pedagógica é um instrumento de promoção da inclusão e da equidade face às diferenças existentes no seio da população escolar, só pode diferenciar e incluir crianças com NEE, quem tiver consciência dos motivos pelos quais diferencia e assentar esses motivos em fundamentos sólidos, evitando assim, as abordagens superficiais e estereotipadas a que se refere (Foshay, 2000, p.9).

\section{Diferenciação pedagógica}

Pacheco (2011,p.89) define a diferenciação pedagógica como "princípio global de organização curricular com vista à resolução dos problemas do fracasso escolar. A mesma ideia é partilhada por Perrenoud (1999, p.56) ao eleger a diferenciação como uma forma de "romper com a pedagogia frontal - a mesma lição, os mesmos exercícios para todos”. Para o autor, a diferenciação assenta no princípio da organização do trabalho e dos dispositivos que colocam a cada um dos alunos a uma 
posição de aprendizagem. Coménio (1985) considera que o currículo jamais será de "ensinar tudo a todos", se tivermos em conta que cada criança aprende de forma diferente, exigindo do professor descobrir a combinação de estratégias e de táticas que correspondam às necessidades e especificidades únicas de cada criança com NEE.

Estas palavras enaltecem as afirmações de Correia, 1997), ao advogar a inclusão como um sistema de apoio providenciado pela equipa multidisciplinar, no sentido de responder às necessidades individuais dos alunos, incluindo as crianças com NEE. Desta forma, entende-se que a diferenciação implica a valorização da diversidade cultural, social e individual, se considerarmos as finalidades da educação e da escola.

O diagrama que se segue apresenta os propósitos para a diferenciação pedagógica.

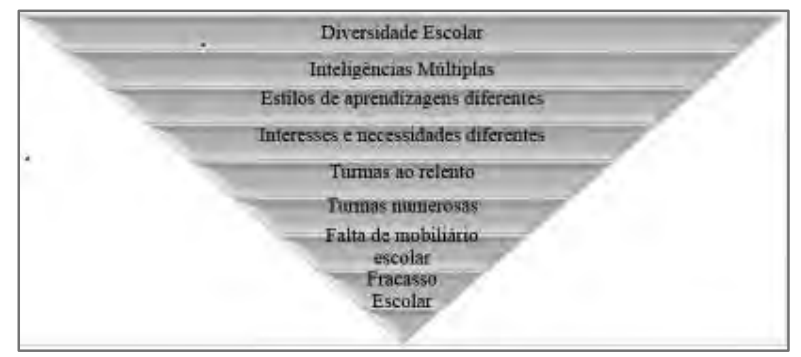

\section{Princípios que Orientam a Diferenciação Pedagógica}

Segundo (Tomilinson e All 2002; Silver, Strong e Perini 2010; Correia, 2013; Pacheco, 2014; Foshay, 2000; Pacheco, 2011) a diferenciação pedagógica orienta-se em quatro categorias. A flexibilização do processo pedagógico que se caracteriza pela docilidade do processo de intervenção pedagógica que aí corre; A avaliação formativa das aprendizagens geradoras de conhecimentos e competências, que têm um papel preponderante no ensino inclusivo; A organização flexível dos grupos na realização das atividades escolares, que conduz os alunos a aceder a uma variedade de oportunidades de aprendizagens e propostas de trabalho; A valorização dos estilos de aprendizagens, que propiciam o rendimento escolar.

O diagrama que se segue mostra as capacidades e processos de aprendizagem.

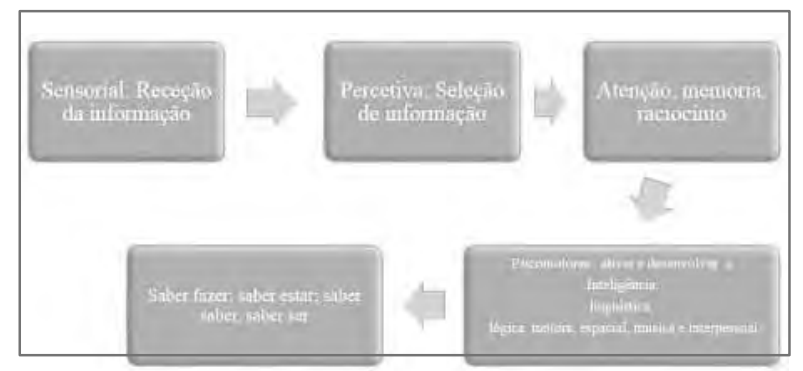

\section{Estratégias de Facilitação da Diferenciação Pedagógica}

Qualquer processo de ensino/aprendizagem para lograr os sucessos almejados, precisa ser planificado e guiado por uma gama de estratégias que norteiam a sua trajetória. Assim, as estratégias são a ferramenta que guiam a arte do professor na sala de aula. Contudo, nenhuma estratégia conseguirá compensar a um professor a quem falta a proficiência na sua área de saber. Desta feita, é indispensável a preparação da aula devidamente, identificar e organizar antecipadamente os materiais didáticos a usar, de forma a evitar aulas expositivas e/ou improvisadas que só prejudicam o aluno e o processo no seu todo. São várias as estratégias que o professor pode usar no seu trabalho docente, todavia sugerimos a concentração da sua atenção para a recetividade e interesse dos alunos, bem como os seus perfis de aprendizagem. O respeito, carinho, atenção e atitude positiva pela diferença é um aspeto indispensável na diferenciação pedagógica. A avaliação e a instrução são elementos inseparáveis no processo de ensino/aprendizagem. Nesta abordagem a avaliação deve ser continuada e formativa, podendo usar várias formas: diários, TPC, portefólios, grelha de avaliação, testes orais e escritos. Pode ainda aplicar questionários de interesse a todos os alunos, onde os conteúdos devem ter sentido para todos eles. O professor/aluno e vice-versa colaboram no processo de aprendizagem: planificam, definem objetivos, refletem sobre o progresso, avaliam o sucesso e os fracassos; o professor estabelece o equilíbrio entre as normas individuais e do grupo; os desafios de trabalhos devem ser exequíveis de acordo com os ritmos de aprendizagem.

\section{Níveis de Diferenciação Pedagógica}

A diferenciação pedagógica ocorre em três níveis de decisão: macro, meso e micro (Sousa, 2010; Pacheco, 2008, 2011 e 2014). A administração central decide os tipos de conhecimentos, os princípios da organização, o grau da estruturação nacional/regional e local bem como os níveis e ciclos de escolarização e cursos. Desenha-se ainda neste nível o plano de formação, os planos curriculares, as disciplinas e programas. O meso ocupase nos projetos educativos que são elaborados ao nível da província/distrital, programas suplementares de apoio pedagógico acrescidos que visam enfatizar ou dar credibilidade à escola na sua missão de ensinar e formar o homem. O último é da materialização, do fazer pedagógico. É o espaço exclusivamente da escola/professor. É onde o professor é chamado a exercer o seu poder, o seu papel e a sua autoridade de mediador das aprendizagens dos alunos. Espaço da produção dos materiais curriculares, da formulação dos objetivos/competências /metas, da abordagem dos conteúdos, da seleção e implementação das estratégias e da realização das avaliações das aprendizagens. 
O diagrama que se segue a presenta os níveis de planificação.

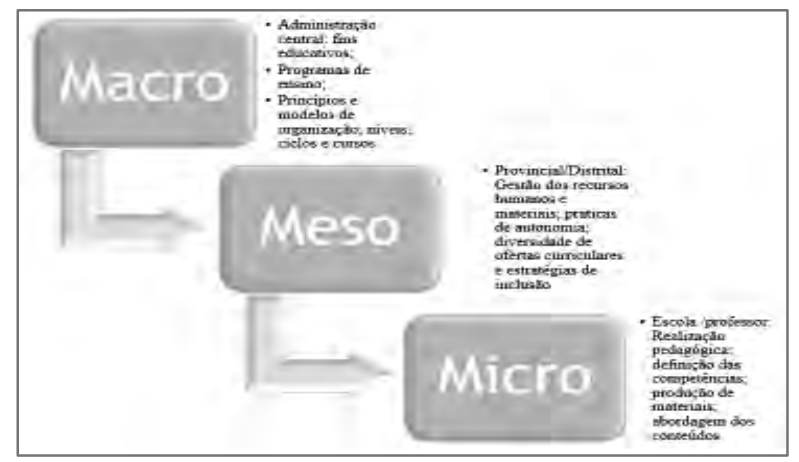

\section{Tipos de Diferenciação Pedagógica}

De acordo com Tomilinson \& All (2002, p. 21), os professores podem diferenciar "os conteúdos, os processos e produtos tendo em conta a recetividade, interesses e perfis de aprendizagem dos alunos”. Como já fizemos menção anteriormente.

O processo de diferenciação pedagógica resume-se na alternância dos conteúdos tendo em conta a natureza dos alunos e o grau das dificuldades que apresentam. Em função disso, o professor planifica atividades diversificadas para a inclusão das crianças na aprendizagem e diferencia em função das necessidades dos alunos, os instrumentos para a verificação da assimilação dos conteúdos. A avaliação das aprendizagens deve ser vista como um processo de análise e autorreflexão, de diálogo, de negociação, de interação entre participantes, baseando-se na discussão de ideias, de pensamentos e harmonização de juízo.

O diagrama que se segue representa os tipos de diferenciação pedagógica.

\section{Metodologia}

O estudo foi orientado pela pesquisa exploratória, para compreender as reflexões dos professores no que concerne ao atendimento das crianças com NEE na sala de aula. Para recolha, de dados trabalhamos com as entrevistas semi estruturadas e observação de aulas a seis professores do EB, quatro formadores dos IFP's e dois técnicos pedagógicos. A análise de conteúdo foi a opção usada para interpretação do conteúdo das entrevistas, das aulas observadas e das leituras feitas nos principais documentos normativos da educação

Em seguida representada a tabela dos colaboradores.

\begin{tabular}{ccccccc}
\hline $\mathbf{N}^{\mathbf{0}}$ & Código & Sexo & Idade & Formação & Experiência & Função \\
\hline 01 & EPB1 & Feminino & 33 & Médio: $10^{\mathrm{a}}+1+1$ & 9 Anos & Professora \\
02 & EPB2 & Masculino & 26 & Médio: $10^{\mathrm{a}}+1$ & 2 Anos & Professor \\
03 & EPB3 & Feminino & 35 & Médio: $10^{\mathrm{a}}+1+1$ & 9 Anos & Professora \\
04 & EPB4 & Masculino & 29 & Médio & 4 Anos & Professor \\
05 & EPB5 & Masculino & 51 & Médio: $10^{\mathrm{a}}+2$ & 33 Anos & Professor \\
06 & EPB6 & Masculino & 32 & Médio: $10^{\mathrm{a}}+1+1$ & 9 Anos & Professor \\
07 & FB1 & Masculino & 46 & Licenciado & 22 & Formador \\
08 & FB2 & Masculino & 48 & Licenciado & 23 & Formador \\
09 & FB3 & Masculino & 34 & Licenciado & 9 Anos & Formador \\
10 & FB4 & Feminino & 39 & Mestre & 15 Anos & Formadora \\
11 & TB1 & Masculino & 33 & Licenciado & 9 Anos & Técnica Ped. Distrital \\
12 & TB2 & Masculino & 52 & Mestre & 30 & Técnico Ped. Central \\
\hline Total & & $10 \mathrm{H}+2 \mathrm{M}=12$ & & &
\end{tabular}

\section{Análise e discussão dos resultados}

Os dados que se seguem refletem as respostas mais significativas encontradas nas entrevistas aplicadas aos colaboradores. $\mathrm{Na}$ categoria "aprendizagens diferenciadoras”, das respostas dadas pelos participantes na pesquisa ficou claro que o termo "diferenciação pedagógica” é desconhecido e/ou interpretado de diversas maneiras:

A diferenciação [....] não estou a ver nada disto aqui, mais sim para incluir mas não tenho base mas sei que existe mas não, não existe, (EBP4)

Que promove a inclusão. A diferenciação como tal não prefiro falar mas inclusão de facto existe documentos até o próprio Ministério de educação tem promovido vários seminários que versam sobre essa matéria de inclusão e recomenda muito que de facto se pratique mais a inclusão. (EBF1).

$E u$ volto a realçar, de diferenciação não prefiro muito falar, mas de inclusão como tal, então perguntava quê? (idem). É que eu entendo que se usarmos o termo diferenciação já estaremos a entregar na exclusão então de facto quer dizer, primeiro esse princípio de enquadra-las naquela turma "normal" já é uma inclusão, segundo a própria criança não sente que há um ensino individualizado, (idem)

Existe uma diferenciação positiva, como posso dizer por exemplo o professor é orientado a dizer aos alunos com dificuldades de audição para sentar a frente, [...], esta excluído de ficar atrás mas no sentido positivo [...] para ele facilitar ouvir. Os 
alunos com problemas de visão que cheguem as a frente para facilitar ou poder coordenar, [...] essas estratégias em termos de organização na sala [...] o professor não usa apenas à linguagem quer dizer que usa a mímica, usa a própria língua dizer usa gestos e isso para poder levar a todos dependendo das condições que estejam. [...] essas atividades precisam mais de cientificidade mais sistematização porque não há nada neste momento que controla: a sua efetivação, cognição efetiva, (EBF3).

Não entendi. Eu acho que o professor ou eu que sou professora contando algumas histórias, (EBP1).

Como se pode depreender, o termo diferenciação pedagógica é algo complexo para os nossos entrevistados, interpretando-o de forma diferente e outros não tem ideia sequer, o significado da palavra.

A segunda subcategoria que evidencia as características da escola inclusiva moçambicana, os entrevistados mostraram-se ansiosos em ver resolvida a problemática de formação de professores, um dos grandes problemas que enferma o setor de educação em Moçambique, vejamos as respostas dos participantes:

É um projeto. Temos base teórica; mas há um grande problema de recursos humanos e materiais para operacionalização; os professores não estão devidamente capacitados e os gestores externos, (técnicos, órgãos subalternos e a inspeção escolar) precisam da formação adequada. Faltam meios na sala de aula, equipamento adequado (EBF2)

É inclusiva, por várias razões: Ao nível da língua, o próprio currículo do Ensino Básico por exemplo permite que os professores usem também a língua da criança para facilitar a comunicação; ao nível das doenças, posso assim dizer acaba por acontecer a inclusão de forma forçada porque as crianças não têm outro sítio para ir. (EBF3).

Os entrevistados caracterizam a escola inclusiva como sendo, um projeto em via de construção. Conclusão o EB moçambicano está longe de alcançar os patamares de uma escola Inclusiva, pois ela requer a criação de bases sólidas para a sua edificação, como testemunham os respondentes:

Nós estamos em processo de mudança no sentido de montar uma escola inclusiva de verdade, a nossa maneira, a nossa moda moçambicana porque na verdade, temos problemas na formação de professores para atender essas crianças. Dentro de 20 a 25 anos a situação pode vir a mudar, (EBF4)
Nós estamos na fase de construção. Os professores têm limitações de formação, de informação. As instituições de formação não estão preparadas, (EBF2)

Ainda está um pouco abaixo por falta de formação e capacitação dos professores para lidar com essas crianças, (EBP6)

Os surdos e mudos só podem aprender através da língua de sinais. Não estão aqui connosco, (EBP2).

Estima-se cerca de 25 anos para que Moçambique tenha uma escola inclusiva com sentido próprio. Tudo depende da vontade do governo, das políticas educativas, do tipo de sociedade que se projeta para o futuro de Moçambique.

\section{Conclusão}

Da análise feita podemos afirmar que a diferenciação pedagógica não é mais uma proposta a introduzir nas práticas escolares, mas antes um imperativo incontornável na sala de aula. Utilizar uma variedade de estratégias de ensino, adaptando as aulas às necessidades e especificidades dos alunos, valorizando os trabalhos individuais e em pares, aumenta o rendimento escolar. A sua focalização no aluno de forma individual permite que as limitações da aprendizagem sejam primeiro diagnosticadas para posteriormente se desenvolver um plano que permita resolve-las. Assim, constata-se porém, que os constrangimentos na implementação do ensino inclusivo moçambicano prendem-se com a formação dos diferentes atores e a insipiência dos recursos financeiros, materiais e humanos para a sua materialização.

\section{Referencias bibliográficas}

Correia, M. (2013). Educação Especial e Inclusão: Quem dizer que uma sobrevive sem a outra- Não está no seu perfeito juízo. Porto: Porto Editora

Harvery, S. Richard, S \& Matthew, P. (2010). Inteligências Múltiplas e Estilos de Aprendizagens: Para que todos possam aprender. Porto: Porto Editora

Pacheco, J. (2014). Educação, Formação $e$ Conhecimento. Porto: Porto Editora

Roldão, M. \& Marques, R. (orgs) (2000). Inovação, Currículo e Formação. Porto: Porto Editora

Sousa, F. (2010). Diferenciação Curricular e Deliberação Docente. Porto: Porto Editora

Perrenoud, P. (1999). Construir Competências desde a Escola a Escola. Porto: Porto Alegre

Tomlinson, C. \& Allan, S. (2002). Liderar Projetos de Diferenciação pedagógica. Lisboa: Editora 